\title{
The effects of low bone mineral density on pain, quality of life and fatigue in patients with epilepsy
}

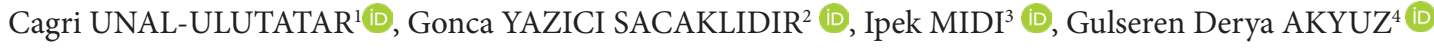 \\ ${ }^{1}$ Physical Medicine and Rehabilitation, Sancak Medical Centre, Istanbul, Turkey. \\ ${ }^{2}$ Physical Medicine and Rehabilitation Clinic, Istanbul Sureyyapasa Chest Diseases and Thoracic Surgery Training and Research Hospital, Istanbul, Turkey. \\ ${ }^{3}$ Department of Neurology, School of Medicine, Marmara University Pendik Research and Training Hospital, Istanbul, Turkey. \\ ${ }^{4}$ Divison of Algology, Department of Physical Medicine and Rehabilitation, School of Medicine, Marmara University Pendik Research and Training Hospital, \\ Istanbul, Turkey.
}

\author{
Corresponding Author: Cagri UNAL-ULUTATAR \\ E-mail: drcagriunal1988@hotmail.com
}

Submitted: 03.01.2021 Accepted: 05.04.2021

\begin{abstract}
Objectives: To investigate the effects of low bone mineral density (BMD) on pain, quality of life (QoL), and fatigue in epileptic patients who use anticonvulsants.

Patients and Methods: Epileptic patients aged 18 years or older who use anticonvulsant drugs were recruited into the study. Demographic and clinical features were recorded, including the duration of epilepsy, number of anticonvulsants used, previous fracture history and BMD scores. The functional parameters included back pain measured with the visual analogue scale (VAS) and brief pain inventory (BPI) scale, QoL assessed with the Qualeffo-41 questionnaire, and fatigue assessed with the fatigue severity scale (FSS).

Results: Of the 100 patients screened for inclusion in the study, 63 epileptic patients met the inclusion criteria. The mean age and mean disease duration of all participants was $39.5( \pm 11.2)$ and $19.3( \pm 11.6)$ years, respectively. The median scores for VAS back pain, VAS low back pain, Qualeffo-41, FSS, pain severity, and pain interference (BPI) were significantly higher in patients with secondary osteoporosis compared to patients with normal BMD. There were significant correlations between lumbar spinal BMD and VAS back pain (rho $=-0.58, \mathrm{p}<0.0005)$, BPI pain severity (rho $=-0.56, \mathrm{p}<0.0005)$, BPI pain interference $($ rho $=-0.52, \mathrm{p}<0.0005)$, Qualeffo-41 (rho $=-0.56, \mathrm{p}<0.0005)$, and FSS (rho $=-0.41, \mathrm{p}=0.001$ ).

Conclusion: Epileptic patients suffering from low BMD showed increased pain, fatigue and impaired QoL. Therefore, BMD measurement should be recommended for the evaluation and management of epileptic patients.

Keywords: Epilepsy, Quality of life, Bone mineral density, Fatigue, Pain
\end{abstract}

\section{INTRODUCTION}

Epilepsy is a chronic disorder with several social and psychological impacts. Patients with epilepsy often report concerns about having a seizure attack, social isolation, adverse effects of anticonvulsants, and transportation/driving restrictions [1]. In general, epileptic patients perform significantly less physical activity and have higher rates of obesity [2]. The reason for reduced physical activity in many patients is that they incorrectly believe that physical activity can induce seizures or increase their frequency, and they may also fear prejudice and perceived social and cultural stigma [3]. However, regular physical activity is important as it increases muscle and bone strength.
In addition, anticonvulsant therapy can negatively impact bone health in several important ways, ranging from asymptomatic high-turnover bone disease to decreased bone mineral density (BMD) and an increased fracture risk [4]. Both children and adults under anticonvulsant treatment have been found to have decreased BMD, often more than two standard deviations below that of healthy young controls [5]. Thus, patients with a history of long-term therapy should be evaluated for anticonvulsantinduced bone disease. Pain, muscle weakness, and skeletal deformities lead to a decrease in QoL in these patients [6,7]. In addition, patients with osteoporosis may have concerns about

How to cite this article: Ulutatar-Unal C, Sacaklidir Yazici G, Midi I, Akyuz D G. The effects of low bone mineral density on pain, quality of life and fatigue in patients with epilepsy. Marmara Med J 2021; 34(3):286-291. doi: 10.5472/marumj.1009016 
falls, fractures and an eventual loss of independence, which could negatively influence their lives $[7,8]$. The use of anticonvulsants that cause low BMD can lead to fragility fractures $[8,9]$. As far as we know, over $60 \%$ of fractures occur in younger women, with T-scores ranging from -1 to -2.5 [10]. Furthermore, all types of fractures are associated with higher mortality rates [11]. Chronic pain, disability, postural changes, and impaired quality of life (QoL) secondary to fractures are commonly observed in osteoporosis; therefore, the assessment and management of pain should be considered in detail [12].

Fatigue related to osteoporosis has not been extensively examined in the literature. In a previous study, osteopenic and osteoporotic patients experienced greater fatigue compared to healthy controls. In patients with a low BMD, there is known to be an interaction between pain, QoL, and fatigue, where a problem in one of these factors can trigger a disturbance in the others [7]. It is important to assess BMD in patients under anticonvulsant treatment. In the literature, there is limited information on the consequences of low BMD in epileptic patients. Furthermore, the effects of low BMD on pain, QoL, and fatigue in patients with epilepsy have not yet been analysed. The aim of this study was to investigate the effect of low BMD on QoL, pain, and fatigue in these patients.

\section{PATIENTS and METHODS}

\section{Participants}

Of the 100 patients screened for inclusion in the study, 63 epileptic patients were included due to the strict exclusion criteria. Seventy-five percent of our patients had generalized epilepsy, the rest had focal seizure. Participants were recruited from the outpatient clinic of Marmara University, School of Medicine Departments of Neurology and Physical Medicine and Rehabilitation. The inclusion criteria were an age of 18 years or older, a diagnosis of epilepsy, and anticonvulsant treatment. The exclusion criteria included Alzheimer's disease, severe psychiatric disorders (bipolar disease, schizophrenia), mental retardation, rheumatologic disorders (rheumatoid arthritis, fibromyalgia, etc.), endocrine disorders associated with osteoporosis (diabetes mellitus, hyper - and hypothyroidism, hyperparathyroidism, pituitary gland disorders, hypogonadism), other medications that can cause osteoporosis (corticosteroids, warfarin, heparin, etc.), malignancy, pregnancy, lactation, and chronic renal/ hepatic failure. Ethical approval was obtained from the Ethical Committee of Marmara University, School of Medicine with a registry number of 09.2016 .367 . Both verbal and written consent were obtained from each participant.

Bone mineral density measurements in the anterior-posterior position were performed at the level of the lumbar vertebra using a dual-energy X-ray absorptiometry (DXA) device (Lunar DPX Prodigy-Tech; General Electric, Madison, WI, USA). Based on the average value for age-matched adult individuals, a $\mathrm{T}$ - or Z-score up to one standard deviation (SD) was considered normal. A T - or Z-score greater than one SD or the presence of a pathologic fracture (vertebral, hip, non-vertebral) was considered secondary osteoporosis [13]. In men under 50 years of age and premenopausal women, Z-scores were used [14].

Demographic data (age, gender, body mass index [BMI], education level), number of births, duration of lactation, presence of menopause, age of menopause onset, regularity of menstrual cycle, alcohol consumption, smoking, and physical activity level were noted. Clinical parameters (disease duration, number of anticonvulsants, type of anticonvulsants) were recorded. The drugs that induce or not cytochrome p450 were classified as inducers, non-inducers, respectively. The drugs that affect bone with other mechanism of action such as valproate classified as others. The participants were requested to complete the following scales: visual analogue scale (VAS) for back pain, brief pain inventory (BPI), quality of life questionnaire of the European Foundation for Osteoporosis (Qualeffo-41), and fatigue severity scale (FSS).

\section{Instruments}

The VAS is a unidimensional measure of pain intensity for the assessment of back pain (VAS back pain). It consists of a 10$\mathrm{cm}$ horizontal line on which the patient's pain intensity is represented by a point between the extremes of "no pain" (score of 0 ) and "worst imaginable pain" (score of 10) [15].

The BPI is one of the most commonly used outcome measures for evaluating pain. The BPI assesses pain severity as "worst", "least", "average", and "now". The pain severity dimension of the BPI consists of four items that are scored from 0 (no pain) to 10 (worst possible pain), whereas the pain interference dimension consists of seven items that are scored from 0 (no interference) to 10 (complete interference). A pain severity score is calculated from the mean of the four pain intensity items, and a pain interference score is calculated from the mean of the seven pain interference items [16]. It has been validated in a Turkish population in surgery patients [17].

The Qualeffo-41 is a disease-specific questionnaire to measure QoL in osteopenia and osteoporosis. It has five domains which are pain (5 items), physical function (17 items), social function (7 items), general health perception (3 items), and mental function ( 9 items). The score for each domain is calculated as an average value of all the answered items linearly converted on a $0-100$ scale. The total Qualeffo-41 score is calculated as the sum of all answers to items and then converted to the 0-100 scale. The QoL worsens as the total Qualeffo-41 score increases [18]. The Turkish version of Qualeffo- 41 has been validated and is commonly used in studies [19].

The FSS contains nine items that evaluate the severity of patients' fatigue symptoms. Each item is scored on a 7-point scale where 1 represents "strongly disagree" and 7 represents "strongly agree". The total score ranges between 9 and 63. The severity of fatigue symptom increases as the total score increases [20].

\section{Statistical Analysis}

Descriptive statistical analyses were performed. The MannWhitney $\mathrm{U}$ test was used to assess the mean differences between groups. Spearman's correlation coefficient was used to assess 
the relationship between continuous parameters. Correlation coefficients $>0.50,0.35-0.50$, and $<0.35$ were considered strong, moderate, and weak, respectively [21]. We were unable to calculate the sample size as there was no previous reference study. Therefore, a post hoc power analysis was performed. Cohen set out standardised measures of effect size, proposing a simple categorisation of small, moderate, and large effect sizes [22]. A formula based on $G$ power version 3.0 was used to determine post hoc power [23]. We determined the power of the study by computing an effect size of 0.80 (large effect) using a significance level of 0.05 . The post hoc power was found to be 0.93 , which is considered good. Hierarchical multiple regression analysis was used to examine the differential contributions of variables to the lumbar BMD score. The variables that were correlated significantly with BMD scores were entered into three models including different categories of variables. Scatterplots of distribution of residuals to the models were found acceptable. SPSS version 20 was used for all statistical analyses, and p-values less than 0.05 were considered statistically significant.

\section{RESULTS}

In total, 63 epileptic patients who were under anticonvulsant treatment (35 females, 28 males) were enrolled in the study. The mean age of participants was $39.5( \pm 11.2)$ years, ranging between 20 and 66 years. The demographic and clinical features of the patients are shown in Table I.

Table I. Demographic and clinical features of the participants ( $n=63)$

\begin{tabular}{ll} 
Gender & $\mathbf{N}(\%)$ \\
Female & $35(55.6)$ \\
Male & $28(44.4)$ \\
\hline Education & \\
\hline Primary-secondary school & $40(63.5)$ \\
\hline High school & $19(30.2)$ \\
University & $4(6.3)$ \\
Presence of fracture & \\
\hline Present & $9(14.3)$ \\
Not present & $54(85.7)$ \\
\hline Age (mean) & Mean (SD), min-max \\
BMI & $39.6(11.2), 20-66$ \\
Disease duration (years) & $26.5(5.1), 15.9-37.2$ \\
Number of anticonvulsants & $19.3(12.6), 3-47$ \\
\hline
\end{tabular}

N: Number; BMI: Body Mass Index; SD: Standard deviation; Min-max: Minimum-maximum

Sixteen female patients were nulliparous. Among the remaining 19 female patients, 5 had one previous pregnancy (14.3\%), 10 had two pregnancies $(28.6 \%), 3$ had three pregnancies $(8.6 \%)$, and 1 patient had four pregnancies $(2.9 \%)$. The mean duration of lactation in female patients who gave birth was $12.4 \pm 17.3$ months. The menstrual irregularity was present in 6 patients
(9.5\%). Eleven female patients (31.4\%) were in menopause. None of the patients were using alcohol, only 5 (7.9\%) of them were active smokers. Regarding anticonvulsant use, 26 (41.3\%) patients were using one anticonvulsant and the rest were using two or more. The patients' scores were compared according to their anticonvulsant types. Inducers, non-inducers and the drugs that effect bone with other mechanisms such as valproate did not differ significantly when scores of BMD, pain, QoL and fatigue compared $(\mathrm{p}>0.05)$. All of the patients were sedentary. The patients with secondary osteoporosis had higher scores of VAS-back pain, BPI-pain severity, BPI-pain interference, Qualeffo-41, FSS compared to the patients with normal BMD which was depicted in Table II.

Table II. Comparison of patients with secondary osteoporosis and normal BMD values $^{*}$

\begin{tabular}{|l|l|l|l|}
\hline & $\begin{array}{l}\text { Patients with } \\
\text { secondary } \\
\text { osteoporosis } \\
(\mathrm{n}=31)\end{array}$ & $\begin{array}{l}\text { Patients with } \\
\text { normal BMD } \\
\text { values (n=32) }\end{array}$ & P value \\
\hline VAS-back pain & $4.9 \pm 3.6$ & $1.2 \pm 1.6$ & $<0.0005^{* *}$ \\
\hline BPI-pain severity & $4.2 \pm 3.1$ & $1.2 \pm 1.6$ & $<0.0005^{* *}$ \\
\hline BPI-pain interference & $4.4 \pm 3.3$ & $1.1 \pm 1.6$ & $<0.0005^{* *}$ \\
\hline Qualeffo-41 pain & $30.6 \pm 26.2$ & $9.8 \pm 15.1$ & $0.002^{* *}$ \\
\hline $\begin{array}{l}\text { Qualeffo-41 physical } \\
\text { function }\end{array}$ & $25.5 \pm 22.2$ & $10.7 \pm 16.3$ & $0.001^{* *}$ \\
\hline $\begin{array}{l}\text { Qualeffo-41 social } \\
\text { function }\end{array}$ & $30.6 \pm 26.2$ & $9.8 \pm 15.1$ & $0.001^{* *}$ \\
\hline Qualeffo-41 GHP & $49.9 \pm 20.1$ & $29.9 \pm 22$ & $<0.0005^{* *}$ \\
\hline $\begin{array}{l}\text { Qualeffo-41 mental } \\
\text { function }\end{array}$ & $50.5 \pm 19.4$ & $26.7 \pm 18.3$ & $<0.0005^{* *}$ \\
\hline Qualeffo-41 total score & $40.7 \pm 18$ & $19.3 \pm 14.9$ & $<0.0005^{* *}$ \\
\hline FSS & $40.9 \pm 18.5$ & $19 \pm 13.5$ & $<0.0005^{* *}$ \\
\hline$*:$ Mann-Whitney U test; & vill &
\end{tabular}

*:Mann-Whitney U test; ${ }^{* *}$ all values were significant; $N$ : Number; BMD: Bone Mineral Density; VAS: Visual Analogue Scale; BPI: Brief Pain Interference; Qualeffo-41: Quality of Life Questionnaire of the European Foundation for Osteoporosis-41; GHP: General Health Perception; FSS: Fatigue Severity Scale

There were significant moderate correlations between lumbar BMD scores and BMI, number of anticonvulsants, VAS back pain score, BPI score, Qualeffo-41 score, and FSS (Table III). The mean BMD score $\left(\mathrm{g} / \mathrm{cm}^{2}\right)$ did not differ between genders $(\mathrm{p}=0.65)$.

A hierarchical regression analysis was used to examine the differential contributions of different independent variables. The overall model accounted for $45 \%$ of variance to the lumbar BMD scores. In hierarchical multiple regression, three models were used. Model 1, demographic and clinical variables (BMI, number of anticonvulsants) predicted the BMD scores since its contribution to the models was $21 \%$ of the variance [F (2, $60)=8.3,(p=0.001)]$. Controlling the BMI and the number of anticonvulsants, the self-reported measures assessing QoL and fatigue contributed significantly, accounting for an additional $12 \%$ of the variance $[\mathrm{F}(2,58)=5.4, \mathrm{p}=0.007]$ (Model 2$)$. The addition of scales that assessed pain (VAS-back pain, BPI-pain 
severity, BPI-pain interference) to the prediction of BMI (Model 3 ) also led to a statistically significant increase in $R^{2}$ of 0.11 , $\mathrm{F}(3,55)=3.8, \mathrm{p}=0.015$. Table IV showed the full details on each regression model.

Table III. Relation of the Lumbar BMD $(\mathrm{g} / \mathrm{cm} 2)$ scores with demographic and clinical parameters $(n=63)$

\begin{tabular}{|c|c|c|}
\hline & $\begin{array}{l}\text { Spearman's } \\
\text { correlation } \\
\text { coefficient (rho) }\end{array}$ & $P$ significance value \\
\hline Age & -0.12 & 0.34 \\
\hline BMI & 0.42 & $0.005^{\star}$ \\
\hline Disease duration (years) & -0.16 & 0.22 \\
\hline Number of anticonvulsants & -0.40 & $0.001^{*}$ \\
\hline VAS-back pain & -0.58 & $<0.0005^{\star}$ \\
\hline BPI-pain severity & -0.56 & $<0.0005^{\star}$ \\
\hline BPI-pain interference & -0.52 & $<0.0005^{\star}$ \\
\hline Qualeffo-41 & -0.56 & $<0.0005^{\star}$ \\
\hline FSS & -0.41 & $0.001^{\star}$ \\
\hline \multicolumn{3}{|c|}{$\begin{array}{l}\text { *Significant values; N:number; BMD: Bone Mineral Density; BMI: Body Mass } \\
\text { Index; VAS: Visual Analogue Scale; BPI: Brief Pain Index; Qualeffo-41: Quality } \\
\text { of Life Questionnaire of the European Foundation for Osteoporosis-41; FSS } \\
\text { Fatigue Severity Scale }\end{array}$} \\
\hline
\end{tabular}

Table IV. Final model for the associations between the lumbar BMD score and the other variables entered in three models

\begin{tabular}{|c|c|c|c|}
\hline Variables & $R^{2}$ change & F change & P value \\
\hline $\begin{array}{l}\text { Model 1: Demographic and clinical } \\
\text { variables } \\
\text { BMI } \\
\text { Number of anticonvulsants }\end{array}$ & 0.22 & 8.2 & $0.001^{*}$ \\
\hline $\begin{array}{l}\text { Model 2: Scales assessing QoL and fatigue } \\
\text { Qualeffo- } 41 \\
\text { FSS }\end{array}$ & 0.12 & 5.4 & $0.007^{*}$ \\
\hline $\begin{array}{l}\text { Model 3: Scales assessing pain } \\
\text { VAS-back pain } \\
\text { BPI-pain severity } \\
\text { BPI-pain interference }\end{array}$ & 0.11 & 3.8 & $0.015^{\star}$ \\
\hline \multicolumn{4}{|c|}{$\begin{array}{l}\text { BMD: Bone Mineral Density; BMI: Body Mass Index; QoL: Quality of Life; } \\
\text { Qualeffo-41: Quality of Life Questionnaire of the European Foundation for } \\
\text { Osteoporosis-41; FSS: Fatigue Severity Scale; VAS: Visual Analogue Scale; BPI } \\
\text { Brief Pain Index; }{ }^{*} p<0.05 \text { accepted as significant }\end{array}$} \\
\hline
\end{tabular}

\section{DISCUSSION}

This study aimed to assess the relationship of BMD with pain, QoL, and fatigue in epileptic patients under medical treatment. Anticonvulsants decrease $\mathrm{BMD}$ and increase the risk of fractures by two-fold due to high bone turnover, and secondary hyperparathyroidism [24]. Epilepsy and its treatment are associated with a decrease in BMD in patients of both genders, independent of vitamin D levels [25].
Hierarchical multiple regression analysis performed to predict the differential contributions of different independent variables. The overall model accounted for $45 \%$ of variance to the lumbar BMD scores. All of the three models contributed significantly to the variance. Chin et al., describes $\mathrm{R}^{2}$ values of $0.67,0.33$, and 0.19 in multiple regression models as substantial, moderate, and weak, respectively [26].

The QoL of individuals with epilepsy is related to their perception of the impact of the disease itself and its treatment. Thus, the QoL of epileptic patients could be negatively affected by the adverse effects of anticonvulsants [27]. Indeed, uncontrolled epilepsy, adverse effects of anticonvulsants, and psychological comorbidities (i.e., depression, anxiety) have been found to negatively affect the QoL of patients with epilepsy [28]. In these patients, QoL is determined by the balance between seizure control by anticonvulsants and their adverse effects. The pain, muscle weakness, skeletal deformities, and psychological disorders associated with osteoporosis may have negative effects on QoL [7]. Furthermore, the pain, anxiety, and depression associated with osteoporosis may cause sleep disturbances in epileptic patients [28]. In accordance to this, the patients with secondary osteoporosis had a decreased mental and social function compared to the patients with normal BMD in our study. Furthermore, we showed that the epileptic patients with secondary osteoporosis had poor QoL.

Chronic pain is one of the most consequential symptoms of age-related and secondary osteoporosis. The most common symptom reported by patients with a diagnosis of osteoporosis is back pain resulting from osteoporosis-related fractures, skeletal deformities, joint imbalance, and tension in muscular structures [12]. Accordingly, epileptic patients with osteoporosis had greater VAS back pain scores compared to those without osteoporosis. Also, there were significant moderate correlations between the BMD scores of epileptic patients and pain severity (rho $=-0.56, \mathrm{p}<0.0005)$ and pain interference $(\mathrm{rho}=-0.52, \mathrm{p}$ $<0.0005)$, assessed using the BPI.

Fatigue is commonly seen in epilepsy and osteoporosis, both of which are chronic conditions $[7,29]$. The frequency of fatigue was $47.1 \%$ in epileptic patients. Fatigue is known to be significantly related to sleep and depression [29]. However, the relationship of epilepsy-related fatigue with $\mathrm{BMD}$ and osteoporosis has not yet been investigated. In our study, epileptic patients with secondary osteoporosis had higher fatigue scores compared to the patients with normal BMD. Furthermore, BMD scores were significantly negatively correlated with FSS scores ( rho $=-0.41$, $\mathrm{p}=0.001)$. As the BMD scores of epileptic patients decreased, the patients complained of greater fatigue (higher FSS score).

In our study, we found that as the number of anticonvulsants increased, lumbar BMD scores decreased (rho $=-0.40, \mathrm{p}=$ 0.001). In accordance with the findings of our study, Farhat et al., found that the multiplicity of anticonvulsant therapies was a significant negative determinant of BMD [25]. We found no correlation between lumbar BMD scores and disease duration. However, Farhat et al., showed that the duration of anticonvulsant therapy was significantly negatively correlated with BMD. Nevertheless, two other studies failed to show a relationship 
between disease duration and BMD. In those studies, the mean duration of disease was longer than that reported by Farhat et al., but similar to our results, so most of the deleterious skeletal effects may have already occurred [25, 30, 31]. Cytochrome P450 enzyme inducers phenytoin (PHT), phenobarbital (PB), primidone (DRE), carbamazepine, oxcarbazepine (OXC) are associated with a decrease in BMD. However, valproate, which inhibits cytochrome $\mathrm{P} 450$ is also associated with decreased BMD suggesting different mechanism of effect on bone metabolism. Previous studies suggested that valproate affects directly the functions of bone cells. New generation anticonvulsants are thought to be less harmful to bone metabolism, however new researches should be carried out to prove it definitely. In our study, we compared the anticonvulsants by mechanism of their action on bone, however no significant difference was found. There was no relationship between age and lumbar BMD scores in our study. This could be attributed to the fact that the participants enrolled in our study were relatively younger, with an age range of 20 to 66 years. As far as we know, osteoporosis is associated with a low BMI $[32,33]$. In accordance with this, we found a positive, moderate correlation between BMI and lumbar BMD scores.

A strength of this study is that several instruments were used to evaluate the deleterious effects of anticonvulsants on BMD, pain intensity, QoL, and fatigue in epileptic patients, which have not been investigated until now. However, the sample size was limited, as most of the epileptic patients treated at our clinic were unable to fill out the questionnaires due to mental problems and various other comorbidities.

\section{Compliance with Ethical Standards}

Ethical approval: This study was approved by the Ethical Committee of Marmara University, School of Medicine with a registry number of 09.2016.367. Both verbal and written consent were obtained from each participant.

Funding: This publication was prepared without any external source of funding.

Conflict of interest: All authors declare that there is no conflict of interest.

Authors' contributions: CUU, and GYS gathered and performed the measurements, IM and GDA were involved in planning and supervised the work, CUU processed the experimental data, performed the analysis, drafted the manuscript and designed the figures. All authors aided in interpreting the results and worked on the article. All authors discussed the results and commented on the article. All authors approved the final version of the article.

\section{REFERENCES}

[1] Martin R, Vogtle L, Gilliam F, Faught E. What are the concerns of older adults living with epilepsy? Epilepsy Behav 2005; 7:297-300. doi: 10.1016/j.yebeh.2005.05.003.

[2] Elliott JO, Seals BF, Jacobson MP. Use of the Precaution Adoption Process Model to examine predictors of osteoprotective behavior in epilepsy. Seizure 2007;16:424-37. doi: 10.1016/j.seizure.2007.02.016. Epub 2007 Apr 18.

[3] Tedrus GMAS, Sterca GS, Pereira RB. Physical activity, stigma, and quality of life in patients with epilepsy. Epilepsy Behav 2017;77:96-8. doi: 10.1016/j.yebeh.2017.07.039. Epub 2017 Oct 12.

[4] Drezner MK. Treatment of anticonvulsant drug-induced bone disease. Epilepsy Behav 2004;5:41-7. doi: 10.1016/j. yebeh.2003.11.028.

[5] Özemir ZA, Yalçın AD. Antiepileptik ilaçların kemik yoğunluğuna ve metabolizmasına etkileri. Epilepsi 2017;23:16. doi:10.14744/epilepsi.2016.93723.

[6] Christiansen C, Rødbro P, Lund M. Incidence of anticonvulsant osteomalacia and effect of vitamin D: controlled therapeutic trial. Br Med J 1973;4(5894):695-701. doi: 10.1136/ bmj.4.5894.695.

[7] Albayrak I, Aydogmus M, Ozerbil OM, Levendoglu F. The association between bone mineral density, quality of life, quality of sleep and fatigue. Acta Clin Belg 2016;71:92-8. doi: 10.1179/229.533.3715Y.000.000.0061. Epub 2016 Feb 8.

[8] Wilson S, Sharp C, Davie M. Health-related quality of life in patients with osteoporosis in the absence of vertebral fracture: a systematic review. Osteoporos Int 2012;23:2749-68. doi: 10.1007/s00198.012.2050-6.

[9] Vestergaard P. Epilepsy, osteoporosis and fracture risk-a meta-analysis. Acta Neurol Scand 2005;112:277-86. doi: 10.1111/j.1600-0404.2005.00474.x.

[10] Cranney A, Jamal SA, Tsang JF, Josse RG, Leslie WD. Low bone mineral density and fracture burden in postmenopausal women. CMAJ 2007;177:575-80. doi: 10.1503/cmaj.070234.

[11] Kanis JA, McCloskey EV, Johansson H, Oden A, Melton III LJ, Khaltaev N. A reference standard for the description of osteoporosis. Bone 2008;42:467-75. doi: 10.1016/j. bone.2007.11.001. Epub 2007 Nov 17.

[12] Catalano A, Martino G, Morabito N, Scarcella C, Gaudio A, Basile G, et al. Pain in osteoporosis: from pathophysiology to therapeutic approach. Drugs Aging 2017;34:755-65. doi: 10.1007/s40266.017.0492-4.

[13] Mirza F, Canalis E. Secondary osteoporosis: pathophysiology and management. Eur J Endocrinol 2015;173(3):R131-R51. doi: 10.1530/EJE-15-0118

[14] Densitometry ISfC. Diagnosis of osteoporosis in men, premenopausal women, and children. J Clin Densitom 2004;7(1):17-26. doi: 10.1385/jcd:7:1:17 [published Online First: 2004/01/27]

[15] Huskisson EC. Measurement of pain. The lancet 1974;304(7889):1127-31. doi: 10.1016/s0140-6736(74)908848.

[16] Cleeland CS. The brief pain inventory: user guide. Houston, TX: The University of Texas MD Anderson Cancer Center 2009:1-11.

[17] Dicle A, Karayurt Ö, Dirimese E. Validation of the Turkish version of the Brief Pain Inventory in surgery patients. Pain Manag Nurs 2009;10(2):107-13. e2. doi: 10.1016/j. pmn.2008.08.002. 
[18] Lips P, Cooper C, Agnusdei D, Caulin F, Egger P, Johnell O, et al. Quality of life as outcome in the treatment of osteoporosis: the development of a questionnaire for quality of life by the European Foundation for Osteoporosis. Osteoporos Int 1997;7:36-8. doi: 10.1007/bf01623457 [published Online First: 1997/01/01]

[19] Kocyigit H, Gülseren Ş, Erol A, Hizli N, Memis A. The reliability and validity of the Turkish version of Quality of Life Questionnaire of the European Foundation for Osteoporosis (QUALEFFO). Clin Rheumatol 2003;22:18-23. doi: 10.1007/ s10067.002.0653-6.

[20] Krupp LB, LaRocca NG, Muir-Nash J, Steinberg AD. The fatigue severity scale: application to patients with multiple sclerosis and systemic lupus erythematosus. Arch Neurol 1989;46(:1121-23. doi: 10.1001/archneur.1989.005.20460115022.

[21] Cohen RJ, Swerdlik ME, Phillips SM. Psychological testing and assessment: An introduction to tests and measurement. California:Mayfield Publishing Co, 1996.

[22] Cohen J. Statistical power analysis for the behavioral sciences. $2^{\text {nd }}$ ed. Hillsdale, NJ: Erlbaum, 1988.

[23] Faul F, Erdfelder E, Lang AG, Buchner A. G*Power 3: a flexible statistical power analysis program for the social, behavioral, and biomedical sciences. Behav Res Methods 2007;39:175-91. doi: 10.3758/bf03193146. [published Online First: 2007/08/19]

[24] Mazziotti G, Canalis E, Giustina A. Drug-induced osteoporosis: mechanisms and clinical implications. Am J Med 2010;123:877-84. doi: 10.1016/j.amjmed.2010.02.028 [published Online First: 2010/10/06]

[25] Farhat G, Yamout B, Mikati MA, Demirjian S, Sawaya R, ElHajj Fuleihan G. Effect of antiepileptic drugs on bone density in ambulatory patients. Neurology 2002;58:1348-53. doi: 10.1212/wnl.58.9.1348 [published Online First: 2002/05/16]

[26] Chin WW. The partial least squares approach to structural equation modeling. In: Marcoulides GA, ed. Modern methods for business research. New York: Psychology Press, 1998:295336.

[27] Berto P. Quality of life in patients with epilepsy and impact of treatments. Pharmacoeconomics 2002;20:1039-59. doi: 10.2165/00019.053.200220150-00002.

[28] Sahin-Onat S, Unsal Delialioglu S, Bicer S, Ozel S. Effects of Sleep Quality on Quality of Life in patients with osteoporosis. Turkish Journal of Osteoporosis 2013;19:32-7.

[29] Kwon O-Y, Ahn HS, Kim HJ. Fatigue in epilepsy: A systematic review and meta-analysis. Seizure 2017;45:151-59. doi: 10.1016/j.seizure.2016.11.006.

[30] Kubota F, Kifune A, Shibata N, et al. Bone mineral density of epileptic patients on long-term antiepileptic drug therapy: a quantitative digital radiography study. Epilepsy Res 1999;33:93-7. doi: 10.1016/s0920-1211(98)00077-1 [published Online First: 1999/03/27]

[31] Stephen LJ, McLellan AR, Harrison JH, et al. Bone density and antiepileptic drugs: a case-controlled study. Seizure 1999;8:339-42. doi: 10.1053/seiz.1999.0301 [published Online First: 1999/10/08]

[32] Ravn P, Cizza G, Bjarnason N, Thompson D, et al. Low body mass index is an important risk factor for low bone mass and increased bone loss in early postmenopausal women. J Bone Miner Res 1999;14:1622-27. doi: 10.1359/jbmr.1999.14.9.1622

[33] Korpelainen R, Korpelainen J, Heikkinen J, Väänänen $\mathrm{K}$, Keinänen-Kiukaanniemi S. Lifelong risk factors for osteoporosis and fractures in elderly women with low body mass index-a population-based study. Bone 2006;39:385-91. doi: 10.1016/j.bone.2006.01.143. Epub 2006 Mar 10. 